International Journal of Agriculture, Environment and Bioresearch

Vol. 4, No. 03; 2019

ISSN: $2456-8643$

\title{
AGE AND GROWTH OF RAY'S BREAM: BRAMABRAMA(BONNATERRE, 1788) FROM THE SOUTH ATLANTIC COAST OF MOROCCO
}

\author{
Jamila Hermas, El Goumri Yassine, Elbahi Abderrafea, Hafidi Najat and Kayaa Abderrazak \\ *Biology department, Faculty of sciences, Ibn Zohr University, Agadir, Morocco. \\ http://doi.org/10.35410/IJAEB.2019.234241
}

\begin{abstract}
The present work is the first contribution to the knowledge of Ray's bream (Bramabrama) biology in the south Atlantic coast of Morocco, which is one ofthe most diverse marine ecosystems in Africa. The aim of this study was to determine age and growth for 101 individuals belonging to the species Bramabrama obtained in fisheries landings of the south Atlantic coast of Morocco. Collected samples consisted of fish with the total length varying from 32.8 to $51.5 \mathrm{~cm}$ and with total weight varying from 528 to $1648 \mathrm{~g}$. Furthermore, the von Bertalanffy growth curve was fitted and the length-weight relationship was calculated. For all lengths, the relationship was linear with a correlation coefficient close to one. The weight-length relationship shows a minor growth relationship and weight increases less than size. Age of each individual was obtained by reading otoliths and age classes from III to XI were represented in the catches. Age classes from VI to IX represented $81.1 \%$, while age classes less than III and greater than XI were not recorded for any sampled fish.
\end{abstract}

Keywords: Ray's bream,Bramabrama, Age, growth, Morocco.

\section{INTRODUCTION}

Bramabrama, commonly known as Atlantic pomfret or Ray's bream, is a bathy- and epipelagic species of the family Bramidae, generally found at depths ranging from 0 to $1000 \mathrm{~m}$ [1].This oceanic and highly migratory species has a cosmopolitan distribution, extending over most of the North and the South Atlantic, Indian and South Pacific Oceans. In the Eastern Atlantic, it ranges from Norway southwards (including the western Mediterranean) to South Africa.

This species is known to breed in the Mediterranean during August and September at water temperatures greater than $20^{\circ} \mathrm{C}[1][2]$. The planktonic eggs of this oviparous speciesare ventilated and guarded by the male who fiercely defends its territory from other males. The female lays between 200 and 300 thousand yellow-orange eggs with a diameter that varies between 1.6 and 2 $\mathrm{mm}[3]$.

Despite its commercial importance, (being widely consumed as fresh fish), little information is available concerning the biology, ecology and population dynamics of Bramabrama. The aim of 
this paper is to provide additional data on the age and growth of this species in the south Atlantic coast of Morocco.

\section{MATERIAL AND METHODS}

In order to determine age and growth of Bramabrama, 110 individual fish were obtained in fisheries landings of the south Atlantic coast of Morocco during the period from September 2017 to May 2018. The fish specimens were kept in ice and then transported to The Oceanography and Fisheries Laboratoryat the Faculty of Sciences Ibn Zohr, Agadir.

Measuring weight and length:

All fish were weighted $( \pm 1 \mathrm{~g})$ using a Balance GX GRAM [min=0.5g, max $=6000 \mathrm{~g}$ ]. For each individual the following length measurements were taken using an ichtyometer graduated in $\mathrm{cm}$ :

Total Length (TL) =Distance between the tip of the snout and the end of the longest part of the caudal fin.

Standard Length $(\mathrm{SL})=$ Distance between the tip of the snout and the base of the caudal fin.

Fork Length $(F L)=$ Distance between the tip of the snout and the fork of the caudal fin.

Determining fish age by readingotoliths:

Otoliths have been used traditionally to obtain information about the age of fish. They are structures located in the inner ear cavity of all teleost fish. The Ray's bream otoliths are small, with a large and opaque nucleus, which is characteristic of fish that spawn in winter or early spring [4].

The sagittal otoliths of our sample were extracted and 9 out of $110(8.1 \%)$ fish were not used because the structure of their otoliths became damaged during the extraction. The pattern in the otolith is composed of a number of concentric shells with different radii. Depending on the amount of organic material in eachshell or zone, its appearance will vary from extremely opaque to completehyaline.

Readings of one otolith from each fish were carried out with stereoscopic microscope SZX10 connected to the "Olympus" image analysis system. Calcium carbonate striations deposited on otoliths can be discerned as annual rings(Fig. 1.), and are therefore useful for determining age of fish. 


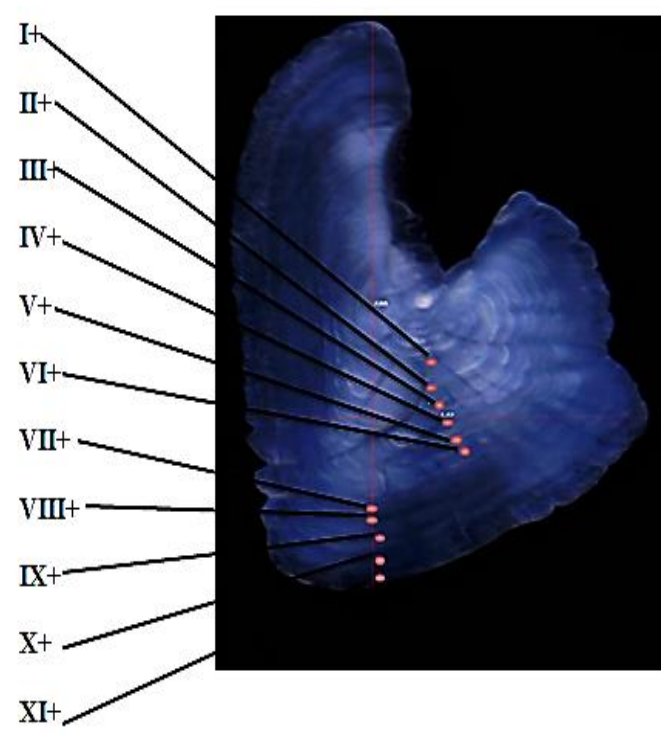

Fig. 1.A section of Ray's bream otolith showing annual growth rings and age classes.

The von Bertalanffy model (1938) is among the models that describe population growth and one of the most widely used models in growth studies in fisheries biology.It is a descriptive mathematical model of age-dependent length growthof fish and represented by the equation:

$\mathbf{L}_{t}=\mathbf{L}_{\infty}\left(1-e^{-K\left(t^{-} \mathbf{t} 0\right)}\right)$

$\mathrm{L}_{\mathrm{t}}$ l length of fish at time $\mathrm{t}$.

$\mathrm{K}$ : the growth rate.

$\mathrm{t}_{0}$ : time at which the fish length equal zero.

$\mathrm{L}_{\infty}$ :the asymptotic length at which growth is zero (termed 'L infinity' in fisheries science).

The parameters of the von Bertalanffy growth equation was estimatedby non-linear least-squares regression. While the relationship between different length measurements of Ray's bream was determined by simple linear regression. The relation between weight and length is presented by the following equation:

$\mathbf{W}=\mathbf{a} \mathbf{L}^{\mathbf{b}}$

W: Total weight $(\mathrm{g})$;

L:Length of the fish (cm).

a:Constant, represents the condition or overweight of the fish.

b:Constant, translates the coefficient of allometry(generally close to 3 ).

\section{RESULTS}

The length-frequency distribution of both sexes of Ray's bream used in our study (Fig. 2) provides demographics data about exploited individuals. Our samples ranged from $32.8 \mathrm{~cm}(528$ g) to $51.5 \mathrm{~cm}(1648 \mathrm{~g})$ and the modal class varies from 39 to $42 \mathrm{~cm}$. 


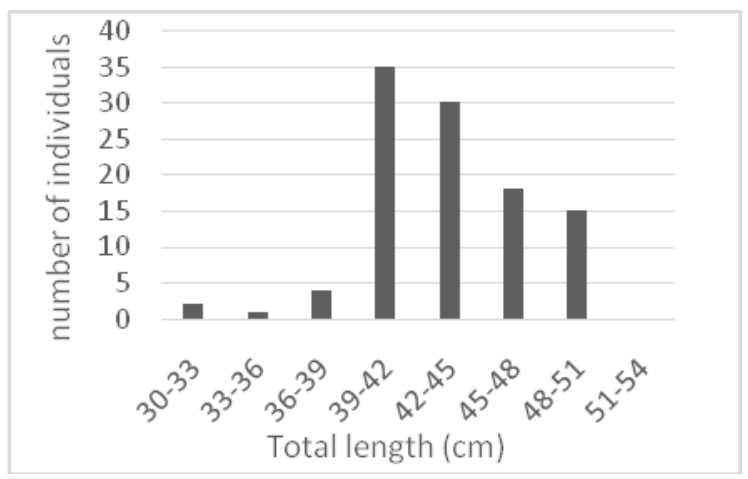

Fig. 2.Length frequency distribution of Bramabrama.

The weight-length relationship was

$\mathbf{W}=\mathbf{0 . 0 2 5} \mathrm{L}^{2.777}$ (Fig. 3).

The comparison between the value of the allometric coefficient (b) and the theoretical value (equal to 3) shows a minor growth relationship, the weight therefore increases less than size.

Relationship between different sizes of Bramabramais shown in Fig. 4. For all lengths, we note that the relationship is linear with a correlation coefficient close to one. The results of statistical analyses showed that the strongest correlation $\left(\mathrm{R}^{2}=0.975\right)$ is recorded for total length-fork length relationship.

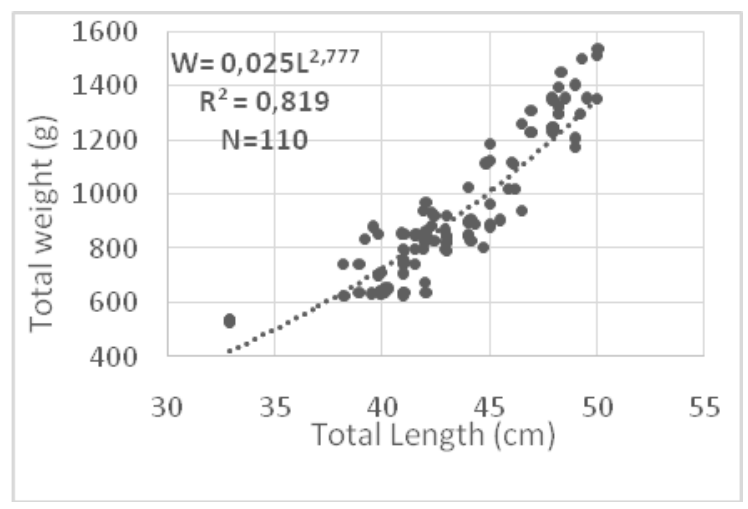

Fig. 3.Weight-length relationship of Bramabrama. 

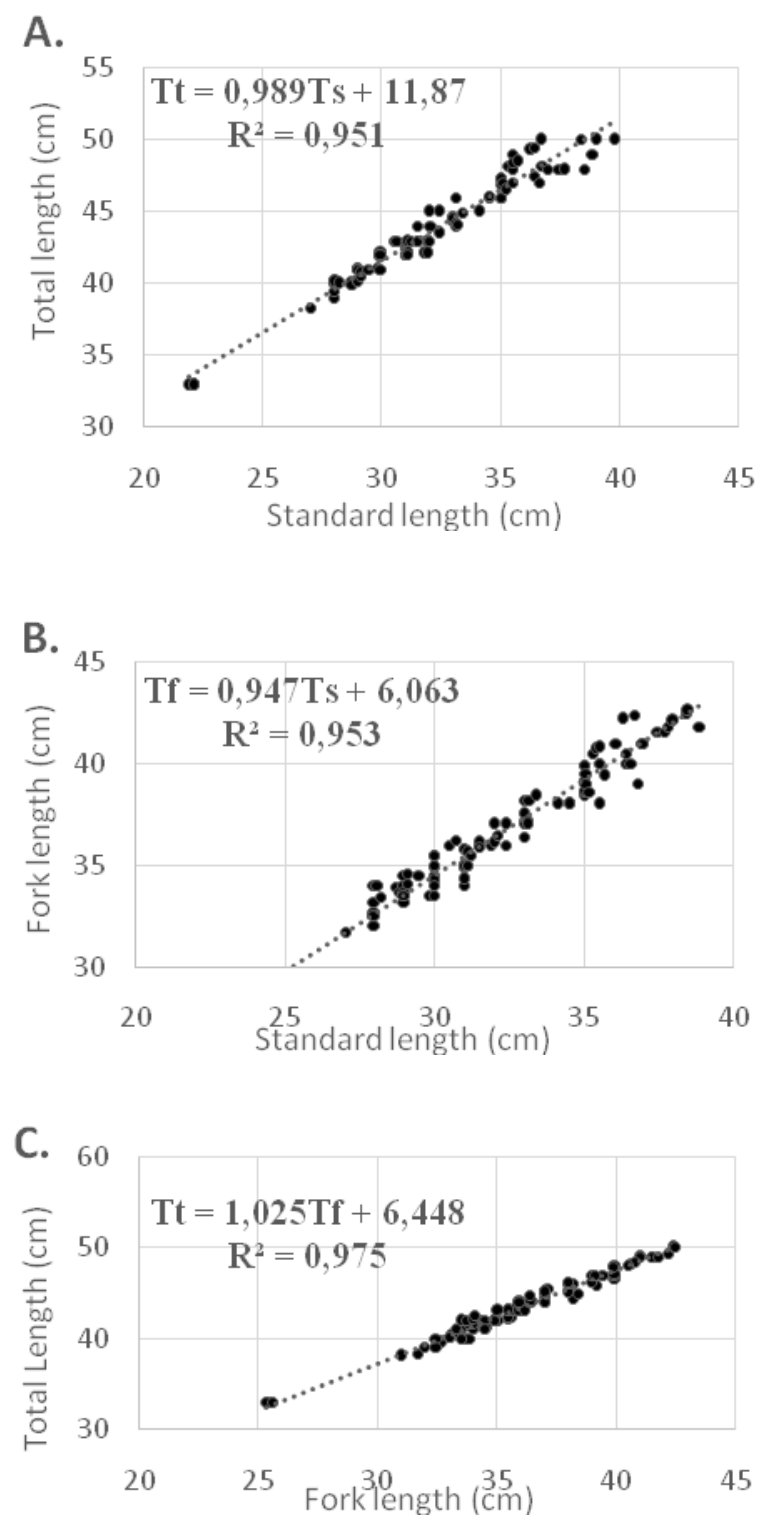

Fig. 4. Relationship between different lengths of

Bramabrama. A: Total length-Standard length, B: Fork length-Standard length, C: Total lengthFork 1

We used an age-length key (Table 1) to estimate the age structure of Bramabrama in the south Atlantic coast of Morocco. In the studied samples, age classes ranged from III to XI and classes from VI to IX represent $81.1 \%$, while age classes less than III and greater than XI were not recorded for any sampled fish.Only two individuals were recorded for the youngest and the oldest age classes. The determination of Ray's breamage by reading otoliths makes it possible to draw the linear growth curve representing age-length relationship (Fig. 5).The observed agelength data and the fitted von Bertalanffy curve are given in Fig. 5. 
The estimated parameters were L $\infty: 61.5 \mathrm{~cm}, \mathrm{~K}: 0.342$ andt $0:-2.418$, giving the following equation:

$\mathrm{Lt}=61.5\left(1-\mathrm{e}^{\wedge}(-0.342(\mathrm{t}+2.418))\right)$

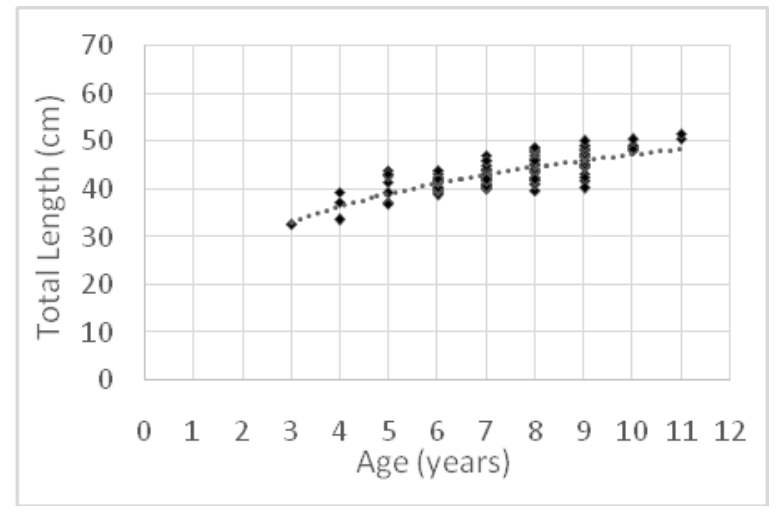

Fig. 5. Linear growth curve of Bramabrama.

\section{DISCUSSION}

The studied fish samples, which we obtained from fisheries landings of the south Atlantic coast of Morocco, ranged from $32.8 \mathrm{~cm}$ to $51.5 \mathrm{~cm}$, with a remarkable absence of small and large individuals, which can be explained by the fact that fish in our sample are all caught using asizeselective fishing method. In addition, the different sizes of the sampled Ray's bream matched perfectly with its marketable sizes.

In our study, the coefficient $\mathrm{k}=0.342$ indicates a relatively low growth rate, knowing that the growth of aquatic species is generallyfast during the early stages of the animal's life, slowing down during the adults stage. This result may be explained by the sampling method, since we worked on a sample that included only marketable individuals, and therefore small individuals are missing in our sample.

Table 1:Age-length key for Bramabrama 
Vol. 4, No. 03; 2019

ISSN: $2456-8643$

\begin{tabular}{|c|c|c|c|c|c|c|c|c|c|c|}
\cline { 2 - 11 } \multicolumn{1}{c|}{} & \multicolumn{9}{c|}{ Age class } \\
\hline Total Length $(\mathrm{cm})$ & III & IV & V & VI & VII & VIII & IX & X & XI & Total number \\
\hline$[30-33[$ & 2 & & & & & & & & & 2 \\
\hline$[33-36[$ & & 1 & & & & & & & & 1 \\
\hline$[36-39[$ & & 1 & 2 & 1 & & & & & & 4 \\
\hline$[39-42[$ & & 1 & 2 & 13 & 10 & 5 & 2 & & & 33 \\
\hline$[42-45[$ & & & 3 & 5 & 9 & 7 & 4 & & & 28 \\
\hline$[45-48[$ & & & & & 3 & 8 & 7 & & & 18 \\
\hline$[48-51[$ & & & & & & 3 & 5 & 5 & 2 & 15 \\
\hline Total number & 2 & 3 & 7 & 19 & 22 & 23 & 18 & 5 & 2 & 101 \\
\hline Mean Tt & 32.8 & 36.7 & 40.7 & 41.26 & 42.58 & 44.26 & 45.88 & 48.92 & 51 & \multicolumn{1}{c|}{} \\
\hline
\end{tabular}

The asymptotic size $\mathrm{L} \infty=61.5 \mathrm{~cm}$

seems normal, as the maximum size observed is $\operatorname{Lmax}=51.5 \mathrm{~cm}$. The asymptotic size Loof our sample has one of the lowest value ever recorded among Ray's bream compared to other studies [5][6][7][8].According to Lobo and Erzini (2001), the fitted vonBertalanffy growth equation adequately describes the growth of Bramabrama individuals present in the south of Portugal. In addition, their results showed that the growth of this species during the adult part of the life cycle is slow $(\mathrm{K}=0.085)$. However, the fitted von Bertalanffy growth curve probably does not provide an accurate description of growth during the first three years of life.

The increase in growth rate and the decrease in asymptotic length islinked to an increase in reproductive investments and perhaps a response to fishing pressure [9]. The comparison between the allometric coefficient and the theoretical value shows a minor growth relationship, the weight therefore increases less than size. Several authors have reported a period of rapid growth during the first years of fish life [10].

\section{CONCLUSION}

The present work represents the first contribution to the knowledge of Ray's bream in the south Atlantic coast of Morocco. The study of growth of Bramabrama individuals showed that, for all lengths, the relationship is linear with a correlation coefficient close to one. The weight-length relationship shows a minor growth relationship and weight increases less than size. The population structure of the studied sample is mainly represented by sizes between 32.8 and 51.5 $\mathrm{cm}$ and age groups between III and XI years.

There is little information available about the Ray's bream, even though it has a commercial importance. Our study in the Moroccan waters emphasises the need for additional sampling programs and continuous monitoring in order to apply statistical methods generally used in the studies of population dynamics. Furthermore, an assessment of the population status is essential for providing the important parameters required to understand its dynamics. Therefore, more research on the Ray's bream is needed to investigate its diet composition, to study its 
reproductive cycle and to better understand the effects of climate variability and ecological disturbances on trophic ecology and migration behavior of this species.

\section{REFERENCES}

[1]Dulčić, J. (1999) 'First record of larval Brama brama (Pisces: Bramidae) and Coryphaena hippurus (Pisces: Coryphaenidae) in the Adriatic Sea', Journal of Plankton Research, 21(6), pp. $1171-1174$.

[2]Quigley, T. (2008) 'Pomfrets ( Bramidae ) in Irish and Northern European Waters Pomfrets (Bramidae) in Irish and Northern European Waters, (45), p. 1.

[3]Rubin, J. (2008) 'des poissons et écrevisses connaissances Module Ligne latérale Narine Barbillons Mâchoire supérieure Opercule dorsale Nageoire adipeuse Nageoire caudale Anus Pédoncule Nageoire anale Nageoire pectorale Tête Nageoire ventrale Tronc Queue', ANATOMIE DES POISSONS, 55, p. 40.

[4]Penttila, J., Dery, L.M., 1988. Age determination methods for Northwest Atlantic species. NOAA Technical Report NMFS72, US Department of Commerce.

[5]QueÂro, J.C., 1984. Les Poissons de Mer des PeÃches FrancËaises.Jacques Graucher (Ed.), Paris, $394 \mathrm{pp}$.

[6]Haedrich, R.L., 1986. Bramidae. In: Whitehead, P.J., Bauchot,M.L., Hureau, J.C., Nielsen, J., Tortonese, E. (Eds.), Fishes ofthe Northeastern Atlantic and Mediterranean, Vol. II. UNESCO,Paris, pp. 847-853.

[7]Bauchot, M.L., 1987. Poissons osseaux. In: Fisher, W., Schneider,M., Bauchot, M.L. (Eds.), Fishes FAO d' identification desespeÁces pour les besoins de la pe ̃̃che, MediterraneÂe et MerNoire, zone de peÃche 37, Vertebres, Vol. II. FAO, Rome,pp. 1000-1001.

[8]Lobo C \& K Erzini. (2001). Age and growth of Ray's bream (Brama brama) from the south of Portugal. FisheriesResearch 51: 343-347.

[9]van Walraven, L., Mollet, F. M., van Damme, C. J. G., Rijnsdorp, A. D. (2010) 'Fisheriesinduced evolution in growth, maturation and reproductive investment of the sexually dimorphic North Sea plaice (Pleuronectes platessa L.)', Journal of Sea Research. Elsevier B.V., 64(1-2), pp. 85-93.

[10]Watanabe, H., Kubodera, T. and Kawahara, S. (2006) 'Summer feeding habits of the Pacific pomfret Brama japonica in the transitional and subarctic waters of the central North Pacific',Journal of Fish Biology, 68(5), pp. 1436-1450 